ÁREA ABIERTA. Vol.13. n². Julio 2013.

http://dx.doi.org/10.5209/rev_ARAB.2013.v34.n2.42623

Referencia: AA35.1207.172

"REESCRITURAS DE PETER PAN: EL HÉROE EN CRISIS"

AUTORA: Silvia HERREROS DE TEJADA

Universidad Antonio de Nebrija y ECAM

\title{
La Reescrituras de Peter Pan: el héroe en crisis
}

\author{
Rewritings of Peter Pan: \\ A Hero in Crisis
}




\title{
RESUMEN:
}

En los albores del siglo XX, el escocés J. M. Barrie creaba a Peter Pan, un personaje de tal éxito que se vio sometido a la adaptación desde muy pronto: el propio autor lo concibió como bebé en su novela El pajarillo blanco para luego, como niño, hacerle protagonista de una obra de teatro y una novela infantil. Tras la muerte de su autor -y en el contexto de las reescrituras tanto literarias como cinematográficas- el héroe siempre mantiene su afán por la juventud eterna y un estado de crisis permanente. Pero, además, obtiene muchas otras características: se transforma en el personaje de un sueño, el ideal del amor juvenil, huérfano dickensiano, joven asesino, un vampiro, padre de familia, un loco, un punki antisistema... En sus nuevas existencias, Peter crecerá para ser joven, adulto y anciano y se adaptará a las cuatro fases de crisis vital que propone la teoría psicosocial acuñada por el psicólogo evolutivo Erik Erikson: la crisis edípica, la de fantasía/realidad; la crisis de identidad de la adolescencia y las crisis adultas (Erikson, 1974). A pesar de la imagen amable que Disney promovió de él y que se mantiene en el inconsciente colectivo, Peter Pan -en las distintas recreaciones- se erige como un héroe en permanente crisis.

\section{Palabras Clave:}

Peter Pan, Crisis, J. M. Barrie, adaptación.

\begin{abstract}
:
At the beginning of the twentieth century, the Scotsman J. M. Barrie created Peter Pan, a character so successful he was subject to interpretation since his early existence: Barrie himself first conceived him as a baby in his novel The Little White Bird to later transform him into the hero of both a play and a children's novel. After the death of his original authorand in the context of literary and film adaptations- the character maintains the eagerness for eternal youth and a state of permanent crisis. But he adopts a series of new traits: he becomes, amongst other things, a dreamed child, the ideal of juvenile love, a Dickensian orphan, a young murderer, a vampire, a family man, a lunatic, a punk... Within his new existences, Peter will grow up to be a youngster, an adult and an old man and will experiment the four crucial crises of psychosocial development as articulated by Erik Erikson: the Oedipal crisis, fantasy versus reality, the teenager identity crisis, and the adult ones (Erikson, 1974). Despite the sweet image portrayed by Disney that remains in the unconscious collective, Peter Pan -in adaptation-emerges as a hero in permanent crisis.
\end{abstract}

\section{Key Words:}

Peter Pan, Crisis, J. M. Barrie, adaptation. 


\section{Introducción}

Peter Pan, al contrario de lo que se piensa, sí quería crecer. Lo que pasa es que no se le dio la oportunidad. En la novela de J. M. Barrie El pajarillo blanco (1902)1', el bebé Peter vive tan contento en los jardines de Kensington bajo el ala del pájaro mentor Salomón Caw, que pospone constantemente el momento de regresar junto a su madre. Está seguro de que -dada la disposición generosa de todas las madres- ésta le esperará con los brazos abiertos. Sin embargo, cuando finalmente se decide, la ventana está cerrada y forjada con barrotes de hierro. A través del cristal, la madre abraza a otro niño... Así que Peter no tiene más remedio que volver a los jardines y adoptar una nueva pose: tomar la firme decisión de que nunca crecerá para convertirse en un hombre.

El narrador intradiegético de la novela -sea Barrie camuflado, o el Capitán W., el hombre soltero que inventa la historia de Peter Pan- reflexiona:

"Ay, Peter, nosotros, que hemos cometido el mayor error de nuestras vidas, deberíamos actuar de manera muy distinta ante la segunda oportunidad. Pero Salomón tenía razón: para la mayoría, no hay segundas oportunidades. Cuando llegamos a la ventana es la hora de cierre. Los barrotes se erigen de por vida." (Barrie, 2009: 97)

Pese a estas solemnes palabras, el héroe de Barrie parece estar atrapado en un mundo de segundas oportunidades. No sólo en el ámbito de la ficción, donde Peter gradualmente crece y se instala en la isla de Nunca Jamás, sino en la propia creatividad de su autor. Aunque las versiones más conocidas del personaje de Barrie son el preadolescente de la obra de teatro Peter Pan o el niño que no quería crecer (1904) y el de la novela Peter y Wendy ${ }^{2}$ (1911), R.D.S. Jack habla de hasta once variaciones del mito (Jack, 2010): once segundas oportunidades de reescribir al personaje en distintos estilos y formatos.

En 1917, J. M. Barrie volvía a preguntarse qué sería de nosotros si se nos diera una segunda oportunidad. En Dear Brutus -cuyo título se inspiraba en la cita de Julio César "¡La culpa, querido Bruto, no es de nuestras estrellas, sino de nosotros mismos, que consentimos en ser inferiores!" -los personajes volvían a cometer los mismos errores de antaño; nadie se salvaba de la culpa. Peter Pan obtendría segundas oportunidades de otros autores, pero ninguno le concedería la redención de volver con su madre, y librarle de su mayor tormento. La culpa -olvidada, sesgada o fomentada-es uno de los rasgos principales que se mantiene en las recreaciones del personaje junto con un estado de crisis permanente $y$ el afán por la juventud eterna. Tres elementos marcados por Barrie en su obra original, y de los que el personaje, a pesar de sus numerosas vidas, ya no se podría desprender.

\footnotetext{
${ }^{1}$ En 1906, se extrajeron los capítulos de la novela adulta que trataban de Peter Pan y se publicaron bajo el título Peter Pan en los jardines de Kensington.

${ }^{2}$ En 1924, la novela pasó a titularse Peter Pan y Wendy para más tarde perder el nombre de la chica y usurpar el título de la obra de teatro, Peter Pan. Existe, pues, cierta confusión bibliográfica al respecto. Las últimas ediciones en castellano reciben el título original que le dio Barrie en 1911.
} 
Para el psicólogo evolutivo Erik Erikson y otros estudiosos influidos por Freud, la vida supone una sucesión de varias crisis a las que el ser humano se debe enfrentar. El propósito de este artículo es demostrar cómo Peter Pan -en las distintas recreaciones- se adapta a las cuatro fases de crisis vital que propone la teoría psicosocial: la crisis edípica, la de fantasía/realidad; la crisis de identidad de la adolescencia y las crisis adultas (Erikson, 1974).

En las versiones de Barrie, como hemos visto, el personaje es bebé, niño y preadolescente. Después, algunos de sus nuevos autores -cineastas, novelistas y dibujantes de cómic-le concederán las edades restantes, la juventud y la madurez. Peter Pan, en su evolución como personaje, no se reduce sólo al simpático niño del filme de Walt Disney (1953) o al joven traumatizado que da pie al síndrome psicológico descrito por Dan Kiley³. Tal y como traslucen estos dos ejemplos, Pan presenta una doble cara: una luminosa (el vuelo, la alegría de la juventud, la despreocupación) y otra oscura, bastante más desconocida. Si en el autor original, se percibían, como describe Celia Wren, los terrores humanos más básicos -el miedo a crecer, la soledad, el tiempo, la libido, los traumas familiares, la guerra entre sexos, la muerte (Wren, 2003: 44-48)- los nuevos autores van más allá y le añaden aún más: la confusión de la adolescencia, el descubrimiento de la propia identidad, el amor, la monstruosidad, la locura.

La gran actitud vital de Peter Pan es ser un niño para siempre y negarse a crecer; un motivo -según la definición de Raymond Trousson- que se convierte en fuente de múltiples temas, una semilla común de la que surgen diversas posibilidades. Peter, como arquetipo de puer aeternus, se mantiene en su rebeldía y este es su "motivo" principal, pero en las adaptaciones, adquiere unos rasgos de personalidad que le llevan, inevitablemente, a hacerlo... Y en la mayoría de las ocasiones, a fracasar en su intento. El proceso vital de Peter Pan, tejido por la imaginación colectiva, lo concibe como un ser en permanente crisis; como es, para Erikson, el mero hecho de existir.

\section{La crisis edípica}

Según la teoría psicosocial, la crisis edípica comprende desde el nacimiento hasta los seis años. Así, en nuestro estudio, incluimos al bebé de Peter Pan en los jardines de Kensington y al héroe de las películas Peter Pan (1953) y Regreso a Nunca Jamás de Walt Disney (2002).

Peter Pan nace como un bebé que, con una semana de edad, escucha lo que le depara el futuro, y decide huir a la isla Serpentina, donde viven los pájaros que luego serán los niños y niñas humanos. Como está convencido de que su madre se ha olvidado de él, adquiere una desconfianza inicial hacia la vida que muy pronto se transforma en

\footnotetext{
3 El doctor Dan Kiley divulgó el síndrome de Peter Pan con su libro de psicología popular The Peter Pan Syndrome: Men Who Have Never Grown Up (1983).
} 
fe. Un equilibrio entre la confianza y la desconfianza que Erikson destaca como una de las virtudes que se dan en los primeros dieciocho meses de vida.

Más tarde -sostiene el psicólogo- a los tres o cuatro años, el niño debe empezar a obtener cierto grado de autonomía, intentando luchar contra sus vergüenzas y sus dudas y alcanzando la virtud de la determinación (Erikson, 1974). Algo que el bebé Peter adquiere con la ayuda del padre sustituto Salomón Caw:

"Lo mejor que le enseñó Salomón fue a tener un corazón alegre. Todos los pájaros tienen corazones dichosos a no ser que se les robe el nido, y como este era el único tipo de corazón que conocía Salomón, le resultó muy fácil enseñar a Peter a tenerlo. El corazón de Peter era tan alegre que tenía ganas de cantar todo el día entero, igual que hacen los pájaros". (Barrie, 2009: 83)

Sin que el autor nos dé ninguna explicación al respecto, el bebé muy mayor, pero que "en realidad, siempre tiene la misma edad" (Barrie, 2009: 79) crece de repente para convertirse en un preadolescente con rasgos infantilizados. Se muda a una isla llamada Nunca Jamás, acoge a unos niños perdidos y en su "edad del juego" se obsesiona con la figura de la madre. En esta etapa, que comprende entre los cinco y los seis años, el niño por primera vez- puede imaginar realidades paralelas a la suya. Es decir, empieza a distinguir entre la verdad y la mentira, desarrolla el concepto de la imaginación y surge la denominada crisis edípica: la renuncia que siente el niño a abandonar su cercanía al sexo opuesto. Peter no entiende que Wendy pueda ser algo más que una madre, y gran parte de su conflicto vital deriva de su ignorancia. Al no ser consciente de la sexualidad (lo que le acerca más a su faceta de niño), su postura es muy ambivalente. Peter Pan quiere una madre y se lleva a una, Wendy, al país de Nunca Jamás. Pero, en realidad, tiene rencor a las madres y una vez allí, Peter juega más a ser el padre de los niños perdidos que el hijo de Wendy. Aún así, cada vez que Wendy le pregunta cuáles son sus sentimientos hacia ella, él, acobardado por lo que implica ser "esposo" siempre responderá "devoción de hijo" (Barrie, 2009: 318) porque su interés en Wendy no conlleva carga sexual alguna. Peter no es consciente de que puede existir otro tipo de relación -que no sea la materno-filialentre ellos y la femenina Campanilla, ante tal impericia, asume la voz del público y grita, desesperada, en su lenguaje de hada: "iSerás imbécil!" (Barrie, 2009: 318).

Según Erikson, en esta primera fase de crisis, un padre tiene que animar a un niño a crecer. Saber que uno, inexorablemente, está destinado a ser adulto es, según el estudioso, uno de los mayores trances del ciclo vital (Erikson, 1974). Una idea que sirve de base a las versiones producidas por Walt Disney, Peter Pan y la secuela Regreso a Nunca Jamás. 


\subsection{Las versiones de Disney}

Aparte de Leonard Maltin, que considera a Disney y Peter Pan "un matrimonio perfecto" (Maltin, 1995: 108), muy pocos críticos resaltan el valor de la adaptación más conocida de la historia. Algo que resulta irónico dado el éxito de público que ha tenido desde el año de su estreno y los beneficios que aún genera. De hecho, la mayoría de la gente identifica al personaje de Barrie como al niño despreocupado, élfico, frívolo y vestido de verde que decidió hacer de él Walt Disney.

Aquí, las decisiones más importantes que se toman para dar forma el personaje recreado son: otorgarle un tono onírico a la historia que dota a Peter Pan sólo de poderes simbólicos, y mantener la trama básica original (en el filme de 1953), pero eliminar gran parte de la profundidad y el tono dramático de la historia, excepto el "detalle significativo" de que Peter se niega a crecer. Además, en cuanto a la caracterización del personaje, éste parece más pequeño que el preadolescente concebido por Barrie: y aunque tiene un aspecto físico de entre nueve o diez años, su actitud se asemeja a la de un niño de alrededor de seis, correspondiente a la fase de desarrollo que Erikson denomina como "edad del juego".

El hecho de que Disney decida concederle a su versión el rasgo que llamaremos todo fue un sueño es determinante $y$, en nuestra opinión, ha condicionado a gran parte de la crítica con respecto a sus adaptaciones. Así, aunque la voz del narrador empiece su relato con un "Todo esto ha sucedido antes, y volverá a suceder" (que apunta a la filosofía mítica de Barrie) enseguida se ve que todos los miembros conocen a Peter Pan y creen en él. A la señora Darling le parece que implica el espíritu de la juventud, John y Michael le convierten en el héroe de todos sus juegos y Wendy se considera la "máxima autoridad" en todo lo que al niño de los cuentos respecta. El hecho de que ella sepa quién es Peter anticipa su llegada y sugiere que la aventura sólo se haya llevado a cabo en la imaginación de la protagonista. Al final del filme, Wendy se despierta tras haberse quedado dormida junto a la ventana y luego, todos los Darling (padres incluidos) ven el barco surcando los cielos. Una imagen que fomenta la idea clave que subyace a toda la película y que se resume en el tema musical principal: "Piensa en tu infancia feliz, tu niñez volverás a vivir". Si hay una estrella que te guía (si se mantiene la inocencia y se cree en la fantasía, a pesar de ser adulto) los sueños se hacen realidad, y Peter Pan es el guardián de esos sueños.

Sin embargo, para que esto suceda hay una condición inviolable: primero hay que crecer. El hecho de hacerse mayor es la única amenaza que existe, y de manera muy explícita, en la película (todo lo demás no supone peligro alguno: indios, piratas, madres que olvidan, rechazo sexual, la posibilidad de la muerte...). La obligación de crecer es el único tema serio que se toca y se repite hasta la saciedad para que quede bien claro. Veamos, algunas líneas de diálogo que se suceden a lo largo del filme y que fomentan dicha idea. Al principio del relato: 
- SEÑOR DARLING (a Wendy): "Señorita, esta será tu última noche en el cuarto de los niños. Y no hay vuelta atrás".

WENDY (a la señora Darling): "Pero, mamá, yo no quiero crecer".

Cuando Wendy se presenta a Peter:

WENDY (a Peter): "Tengo que crecer mañana".

Resentido ante su regreso, Peter amenaza a Wendy:

PETER (a Wendy): "Vuelve a casa y crece. Una vez que crezcas, ya no podrás volver nunca más". ${ }^{4}$

La conclusión y "mensaje" de la película:

WENDY (al señor y la señora Darling): "Ya estoy lista para crecer".

Una amenaza -hay que crecer- tan rotunda que se convierte en el leitmotiv de la película. Wendy viaja a la isla de la imaginación huyendo de la amenaza de que tiene que crecer al día siguiente. Allí, se encuentra con Peter Pan, que se sintió tan atemorizado al respecto, que decidió ser un niño para siempre. Erikson sostiene que un niño que demuestra miedo hacia su futuro como adulto, se siente culpable y se puede volver cruel. Elemento soterrado en el personaje de Disney, pero presente en su altanería inocentona y en su desprecio (siempre subliminal) hacia Wendy.

En esta versión, Peter Pan conserva el corazón alegre de los pájaros que vivían en los jardines de Kensington, pero por otro lado, vive en lo que Erikson define como una de los mayores conflictos del ser humano: la determinación -en Disney, más feroz que nuncade negarse a crecer y permanecer en una eterna crisis edípica.

\section{La crisis de la "fantasía/realidad"}

La segunda crisis del ciclo vital humano se da en la preadolescencia; es decir, entre los siete y los doce años. Esta fase aparece ilustrada en dos obras de Barrie (Peter Pan o el niño que no quería crecer, 1904, y Peter y Wendy, 1911); y la saga de seis cómics del dibujante francés Loisel (1990-2004).

Hasta hace alrededor de cuatro décadas la psicología evolutiva no establecía diferencia entre la preadolescencia (o pubertad) y la adolescencia. En la actualidad, sin embargo, se considera una etapa decisiva y única del desarrollo5. Según Erikson, en la preadolescencia comienza a surgir el descubrimiento del yo psíquico, donde el individuo

\footnotetext{
${ }^{4}$ Nótese que en el original de Barrie nadie amenaza a Wendy directamente con crecer, más que el propio Peter Pan al final del relato.
} 
empieza a interesarse por su mundo interior y por lo tanto, experimenta -por primera vez en su vida- sentimientos de gran soledad. Al surgir un nuevo sentido de la individualidad, comienza a reflexionar sobre sí mismo y a juzgarse: es probable que no se sienta del todo satisfecho consigo mismo, pero no por ello deja de sentirse importante. El púber, al igual que el adolescente, se sobrestima a sí mismo, aunque finja que no es así, y espera constantemente el reconocimiento ajeno. Se siente importante porque es capaz de comprender el mundo y ciertos valores absolutos, como la verdad, la justicia o el amor. Se vuelve tajante porque ahora cree reconocer la complejidad de la vida; pero, al mismo tiempo, tiende a generalizar y simplificar, con lo cual las cosas pierden matices y se vuelven maniqueas. Por un lado, el preadolescente es prepotente; pero, por otro, tiene cierta tendencia a la melancolía y al pesimismo. Sensaciones nuevas que, de alguna manera, le gusta experimentar y que le sumergen en una profunda crisis entre fantasía y realidad (Erikson, 1974).

De hecho, como ya hemos visto en Barrie, Peter Pan no crece porque no puede volver a casa, pero nos hace creer que no crece porque no quiere. Se siente solo en la isla de Nunca Jamás, pero nos convence de que no hay mejor vida posible. Está donde está porque su madre cerró la ventana. Pero su fantasía, ya cierta, es que abandonó el mundo real por elección propia. Escucha las historias en las que él es un protagonista de vida feliz porque fuera se ignora la verdad de su tragedia.

\subsection{El Peter Pan de Loisel}

Loisel, por su parte, en su saga de enorme éxito en Francia, crea a un Peter salido de un Londres dickensiano que vive con su madre, una prostituta odiosa. Harto de la corrupción del mundo adulto, el niño huye a la isla de los seres mitológicos que pueblan la imaginación humana. Una vez allí, Peter se convierte en otro ser imaginario: un niño que nunca crece y que guarda cierto parecido físico con el de Disney. Alrededor de ocho o nueve años, cabello rojizo, nariz respingona, ojos simpáticos y sonrisa pícara. En Nunca Jamás, nadie parece tener mucha memoria... Y resulta paradójico que los seres fantásticos se quejen de ser olvidados cuando ellos apenas tienen recuerdos. El Peter Pan de Disney vive en un presente eterno (como demuestra Regreso a Nunca Jamás, donde se ve que no ha cambiado ni un ápice ${ }^{6}$ ) y el de Loisel se sumerge en un mundo donde el tiempo no avanza, porque todo lo que hace que el tiempo pase -infortunios, traumas, aflicciones, dramas, anagnórisis- se olvida.... aunque igual permanezca en un rincón (muy recóndito) del corazón.

\footnotetext{
${ }^{5}$ La pubertad no fue estudiada en detalle por Freud ni Piaget, pero autores posteriores (Peter Blos, Erik Erikson y Harry S. Sullivan) la resaltaron como etapa fundamental del desarrollo del ser humano.

${ }^{6}$ En Barrie, supuestamente, tampoco cambia con el tiempo, pero sí que lo hace en Cuando Wendy se hizo mayor: una ocurrencia tardía, donde se le ve temeroso y frágil durante unos breves instantes.
} 
Loisel entra en temas ignorados por Disney. Y es que cuando el centauro le advierte a Peter, "estás en un mundo real pero que es imaginario para el mundo de donde vienes" (Loisel, 2004: 52) o "todas las historias son ciertas, Peter, especialmente las que uno se molesta en imaginar" (Loisel, 2004: 54), entramos en una ambigüedad bastante más acorde a la del personaje original. Porque, ¿̇acaso no da a entender Loisel que todo este mundo podría pertenecer a la fantasía particular de Peter?

Hay varios datos que hacen dudar al lector: el mundo está compuesto por los seres mitológicos que él conoce por el único libro que tiene; Peter enseguida adopta el rol de líder sin grandes dificultades; va y viene entre los dos mundos sin dificultad alguna; sueña con matar a su madre y su madre acaba muriendo en el mundo de verdad; y sobre todo, en la isla de la imaginación, se encuentra a un padre idealizado al que lleva echando de menos toda su vida.

El Peter Pan de Loisel, igual que el de Barrie, encierra una hermosa contradicción, ya que precisamente en la tierra de los sueños, el niño se verá obligado a liderar un grupo, sentirá deseos de matar, tendrá que lidiar con la culpa y con decisiones determinantes para su vida (como por ejemplo, decidir si asume que Garfio es su padre, u olvidarlo para continuar jugando eternamente). En otras palabras, Peter en Loisel está madurando todo el rato, lo cual también implica crecer. El autor se esfuerza en explicarnos algo en lo que ni Barrie ni Disney se explayan -por qué un niño querría dejar de crecer- para explicarnos el proceso de maduración peculiar de su versión del mito. Como si su Peter hubiese crecido, pero de otra manera, estancado en la crisis entre fantasía y realidad que propone Erikson.

\section{La crisis de identidad}

Para Erikson, la edad comprendida entre los doce y los veinte años supone posiblemente la etapa más importante de la vida, ya que aquí la tarea primordial de la persona es, de alguna manera, "inventarse" y moldear una identidad del Yo (quién soy y cómo encajo en el resto de la sociedad) a la vez que evitar una confusión de roles. Al tiempo que se va inventando, el adolescente suele desarrollar una lealtad a lo que le gusta. Pero también existen tendencias de mala adaptación: el fanatismo, donde se cobra tanta identidad que no se aceptan otras formas de pensar; o el repudio o falta de identidad, que alude a aquellos que se rebelan contra la necesidad de ser alguien y prefieren ser "malo" a no saber quién se es (Erikson, 1974).

Dentro de las recreaciones adolescentes del héroe, hay dos vertientes de la adolescencia de Peter: una más luminosa o virtuosa, y otra más oscura. 


\subsection{La adolescencia luminosa}

Esta fase está ejemplificada en la saga literaria de Peter y los cazadores de estrellas de Dave Barry y Ridley Pearson (2006-2009) y el filme Peter Pan de P.J. Hogan (2003), donde Peter es un joven de entre trece y quince años, puro de corazón, intolerante, pícaro e idealista que se ve azotado por las emociones amorosas, confusas y sublimes, típicas de la adolescencia.

En Peter y los cazadores de estrellas, best seller en Estados Unidos, Barry y Pearson le arrancan a su personaje el hacha de guerra: su Peter no crece porque un elemento sobrenatural, el poderoso polvo de estrellas, lo ha provocado. En principio, no tiene nada que ver con una postura de rebeldía; pero poco a poco, no tendrá más remedio que defender su nueva forma de vida ante aquellos que le atacan y sobre todo, ante su amada Molly, que crece $y$, por lo tanto, se va alejando de él. En esta saga, el sinvergüenza poco terrenal creado por Barrie se transforma en un chaval simpático y enamoradizo con un alma muy distinta a la de su mítico predecesor.

Según Maria Nikolajeva, en la actualidad se tiende a ofrecer a los lectores un objeto de identificación psicológicamente aceptable que se parece a una "persona de verdad" y que se adhiere al arquetipo grotesco que representa el sujeto que se encuentra en pleno proceso de crecimiento. A su vez, el patrón narrativo más habitual es que el personajearquetipo caiga en algún tipo de exclusión por su incapacidad de reconciliar su libertad personal con las exigencias de la sociedad (Nikolajeva, 2001). Una característica que funcionó muy bien en las novelas de Barry y Pearson pero que Hogan rechazó llevar a cabo en su película, increíblemente fiel a Barrie a pesar de proporcionarle unos cuantos años de más a su protagonista.

El Peter Pan de Hogan no fue el éxito que se esperaba. Esta versión, pensada más para un público adolescente que infantil, fomenta el romance de Peter y Wendy y la noción de que éste último pueda ser, al igual que su antagonista Garfio, un ser incompleto. La mayoría de la crítica señaló el error de elegir como protagonista al actor Jeremy Sumpter, de catorce años. En sus manos, Peter parece un cretino petulante que probablemente encantará a los niños pero irritará a los adultos. Algo que la crítica no supo ver como la mismísima esencia del adolescente prototípico acuñado por Barrie. Peter Pan, hasta ahora, siempre había sido representado por una chica o por un dibujo animado; ninguno de los cuales, evidentemente, podía crecer para convertirse en un hombre. El personaje de Hogan es más adolescente que el concebido por Barrie precisamente para profundizar en su dilema: aquí, Peter Pan está más cerca que nunca de convertirse en un hombre, lo cual hace que su duda sea mayor.

En las obras de Barrie, Wendy siempre le preguntaba a Peter cuáles eran sus sentimientos hacia ella y él tenía una sola respuesta: los de un hijo devoto. En el Peter Pan de Hogan, sin embargo, este mismo conflicto cobra una mayor importancia, ya que, por ser el protagonista un adolescente, es más doloroso. Veámoslo en el siguiente diálogo: 
- Wendy: "Peter, ¿̇Cuáles son tus sentimientos?

- Peter: "¿Sentimientos?"

- Wendy: "¿Qué sientes? Felicidad, tristeza, celos..."

- Peter. "¿Celos? Campanilla..."

- Wendy. "ilra?"

- Peter (Pisa una rama): "Garfio".

- WENDY: "¿Amor?"

- Peter: "¿Amor?"

- Wendy:"Amor."

- Peter:"No sé lo que es eso."

- Wendy: "Yo creo que sí, Peter. Seguro que tú también lo has sentido por algo... O por alguien."

- Peter:"Nunca. Hasta la palabra me revienta."

- Wendy: "Peter..."

- Peter: "¿Por qué lo estropeas todo? ¡Nos lo pasamos bien! ¡Te he enseñado a luchar y a volar! ¿Qué más puede haber?"

- WendY: "Aún hay mucho más."

- Peter: "¿Qué? Dime, ¿̇qué más hay?"

- Wendy: "No lo sé. Me parece que se sabe cuando se crece."

- Peter: "Pues yo no pienso crecer y tú no puedes obligarme [...]. Vete

a casa y crece y llévate tus sentimientos." (Hogan, dir., 2003)

Si Peter siguiese sus instintos y se rindiera ante su amor por Wendy, estaría renunciando a esa identidad que acaba de forjar como adolescente: su empeño en no querer crecer. Por primera vez, asoma una duda terrible en el personaje... Con respecto a la cual $-\mathrm{y}$ como buen adolescente- Peter decide jugar el rol de vencedor.

\subsection{Peter Pan de rojo escarlata}

Entre la luz y la oscuridad de las recreaciones adolescentes, hay una que se queda entre medias: Peter Pan de rojo escarlata (2006), la secuela que encargó el hospital infantil Great Ormond de Londres para celebrar el centenario de la aparición de Peter Pan en el teatro. Un concurso que ganó la autora Geraldine McCaughrean y donde Peter es un niño/hombre iracundo descrito como "era y no era Peter Pan"(McCaughrean, 2006: 41).

En esta novela, Garfio establece que "En el momento que un niño contesta a la pregunta "¿qqué quieres ser de mayor?" ya está muy cerca de convertirse en adulto" (McCaughrean, 2006: 203). Al tener Peter tan claro que él de mayor no quiere crecer, la autora -aún pretendiendo ser fiel al original- le otorga una madurez nueva, y bastante oscura. Aquí, Peter está cambiado: de mal humor, más vanidoso, menos rubio, aburridísimo de su vida en la isla, algo que cuando era más pequeño, en Barrie, no le pasaba nunca. 


\subsection{La adolescencia oscura}

La adolescencia, o lo que es lo mismo, la transformación del niño en adulto tiene -como establece el crítico Kenneth Kidd- algo de monstruoso (Kidd, 1996). Por ello, surgen tantas reinterpretaciones de un Peter realmente obsesivo, atormentado y temible.

En las recreaciones del Peter Pan adolescente y oscuro, la verdadera personificación del enemigo no está en el mal ajeno, sino en la transformación que se sufre y sobre todo, en las debilidades que uno descubre en su interior. La pregunta que sobrevuela a la encarnación de Peter Pan como joven rebelde es terrorífica y reveladora: ¿Qué pasa si de adolescente uno se convierte en alguien que no desea?

En Neverland de Damion Dietz (2003), Nunca Jamás es un parque de atracciones decadente en el que viven Peter y otros delincuentes juveniles sin hogar que se dedican a drogarse con polvo de hadas, a festejar el subidón en los carruseles y a comer algodón de azúcar. Campanilla es una traficante alcoholizada que lleva alas de seda cosidas a la ropa; Tigridia, una transexual que hace el mismo espectáculo de danza india noche tras noche y Garfio, el jefe de mantenimiento del parque: un viejo gay aficionado al sadomasoquismo que está deseando atrapar a los jovencitos escondidos para someterles a un peculiar rito de tortura sexual y al que Peter, antes de ser violado, apuñala.

Este Peter Pan tan sexual, drogado y aterrador se enfrenta a una dicotomía que afecta a muchos jóvenes de la sociedad actual: enfrentarse a su sombra; es decir, atreverse a ser uno mismo o no, ya se sea normal o desviado. Peter es vulnerable porque se busca a sí mismo, pero terrorífico por lo que se ve capaz de hacer. Peter tiene muy claro que no quiere llegar a ser ni Garfio, ni Campanilla. "La tragedia de Peter Pan" -matiza el director de Neverland- "y la de tanta otra gente, no es que rechacen las convenciones, sino que rechacen su 'sombra', esa parte de su alma que les aterra" (Dietz, 2010).

La novela The Child Thief de Gerald Brom convierte a Peter en un ser anhelante que deambula por los barrios y parques más marginales y peligrosos de Nueva York en busca de niños muy perdidos: adolescentes sin esperanza que sufren abusos sexuales, problemas de drogas, o están atrapados en bandas. Peter los "seduce" para que le acompañen a un mundo mejor, donde su misión va a ser asesinar a los adultos que les han "estropeado" la vida. Así, Peter se considera a sí mismo como benefactor de estos jóvenes, pero lo que hace es convertirles en asesinos.

La idea del personaje como supuesto benefactor se explora también en The Lost Girls ${ }^{7}$ novela de la norteamericana Laurie Fox- donde se explora la maldición que asola a varias generaciones de mujeres de la familia Darling. Son disfuncionales e incapaces de tener historias de amor porque sólo se enamoraron una vez: cuando conocieron, de adolescentes, al Peter Pan de Nunca Jamás, un ser arrogante y pagado de sí mismo que

\footnotetext{
${ }^{7}$ No confundir con la novela gráfica Lost Girls de Alan Moore, que relata, de manera muy sexualmente explícita, los despertares eróticos de Wendy, Dorothy de El Mago de Oz y Alicia de Alicia en el país de las maravillas.
} 
es fiel a las chicas Darling (sólo se relaciona con ellas) pero a la vez, las repudia cuando ellas le plantean una historia de amor de verdad. Este Peter está tan confuso y es tan monstruoso que directamente provoca la esquizofrenia en las descendientes de Wendy, hartas de ser concebidas sólo como una madre

De hecho, la primera versión de Jóvenes Ocultos de Joel Schumacher (1987) contaba la historia de una panda de vampiros que buscaban una madre, con muchos ecos de Peter Pan. Finalmente se decidió parodiar la transformación adolescente con la de hombre a vampiro y a tratar la problemática que se establece cuando un adolescente no tiene unos roles claros que seguir. La narración se coloca en el punto de vista de los niños y adolescentes, que consideran a los adultos como seres inútiles (y aquí, desde luego, lo son). En esta película, todos los adolescentes que aparecen (sean vampiros o no) son niños muy perdidos, de ahí su título original: The Lost Boys.

Por último, el personaje del cómic del dibujante Max, Peter Pank, es un punki de rasgos aguileños y maneras radicales que se ríe de tanta oscuridad adolescente para regodearse en los placeres de la juventud: básicamente, un vigor sexual desaforadísimo. Su lección está clara: "Si no puedes cambiar tu sociedad... iperviértela!" (Max, 1991: 25).

Esta crisis de identidad en varias facetas parece representar al personaje en su lado más puro; y de ahí que sea en esta fase donde surgen más reinterpretaciones. Lejos del niño inocente deseado por Barrie y ejecutado por Disney, el Peter Pan adolescente -sumido en un estado inamovible de duda, confusión y crepúsculo- parece ser la escritura más pura del personaje; donde mejor se reconoce a Peter Pan.

\section{Las crisis adultas}

En las recreaciones del Peter Pan adulto, no se pierde el concepto de la vida eterna que caracteriza al personaje, ya que existe como el perenne anhelo que mueve su vida. Los tres hombres fueron adolescentes con la virtud de la vida eterna, pero decidieron renunciar a ella: Jack, en la novela rosa de Mary Alice Kruesi Second Star to the Right (1999); Peter Banning en el filme Hook de Steven Spielberg (1991); y el anciano Don Pedro en la novela infantil de Paloma Orozco (2005).

En las tres fases de la vida adulta se manejan varias crisis. Así, el adulto joven (entre los veinte y los treinta y pocos años) debe desarrollar la intimidad: es decir, ser partícipe de la sociedad y poder estar cerca de otros, ya sean amantes, amigos, o compañeros de trabajo. Se supone que uno ya sabe quién es en esta etapa pero, en numerosas ocasiones, surge una confusión de roles parecida a la de la adolescencia que ahora se refleja en un síntoma distinto: el miedo al compromiso. Éste es el conflicto principal de Second Star to the Right, novela rosa de Mary Alice Kruesi, donde Jack -un personaje que en su infancia fue el niño creado por Barrie- sufre el síndrome de Peter Pan y se niega a tener una relación sentimental madura. 
Por otro lado, para el guionista James $\vee$. Hart, lo más fascinante de escribir Hook fue redescubrir, como adulto, una nueva verdad sobre el héroe que se solapaba con la verdad que había conocido durante años. "Creo que tenía a Peter Pan incrustado como un código genético. (...) Me sorprendió muchísimo lo diferente que era de Walt Disney (...)" (en Sheehan, 2001: 272). Por eso construyó una tercera verdad con respecto a Peter Pan y lo convirtió en Peter Banning, un adulto de alrededor de cuarenta años controlador, ambicioso, atormentado por el paso del tiempo e incapaz de cumplir sus funciones de padre. En principio, todo lo contrario a Peter Pan pero también una consecuencia lógica del personaje.

Según Erikson, al volcarse en cuidar a otros, el adulto de edad media (entre treinta y cinco y sesenta años) se pregunta cuál es su misión o su propósito en la vida y se olvida de aquellos por quienes, en teoría, está haciendo el sacrificio. Así, pues, surge el pánico a envejecer y a no haber logrado las metas que anhelaba de joven, con lo que intenta recuperar su juventud. En la versión final del guión que se rodó (reescrito por Malia Scotch Marmo según las órdenes de Spielberg), se eliminaron varias de las aportaciones que hacía Hart en su primera aproximación a la historia: una, presentar a un Peter y a un Garfio de la misma edad y con el mismo conflicto (y que, de hecho, se fusionan en uno solo); dos, describir una crisis de mediana edad con todo lo que conlleva (Peter tiene un romance real con Campanilla, flirtea abiertamente con las sirenas), aspectos atenuados en la versión de Spielberg, más centrada en una reconciliación con las maravillas de ser padre; y tres, darle una calidad más realista al filme (y no la de pantomima que, inevitablemente, refleja la película definitiva).

Hook, finalmente, se simplifica para convertirse en la historia de un hombre que tiene que rescatar a sus hijos secuestrados y recuperar la esencia del niño que fue. Spielberg, deseando reconciliar a su personaje con las virtudes correspondientes a la edad, reconcilia a Peter con la paternidad convirtiéndolo en un adulto medio tan perfecto trabajador, amante incondicional y solícito- que algún crítico hasta habló de "vergüenza ajena" (Baxter, 1996: 368).

Tras las encarnaciones de Peter Pan como adulto joven que aprende a compartir su intimidad con una pareja y adulto medio que acepta su rol de padre, la escritora infantil Paloma Orozco recrea al personaje en la última etapa del ciclo vital perfilado por Erikson: la de adulto tardío o anciano. En La Sombra de Peter Pan, Don Pedro es un anciano que vive con la también anciana Señora Bell, y que recoge a varios niños huérfanos de entre ocho y nueve años para enseñarles a "volar" con su imaginación. Erikson, de hecho, sostiene que a medida que el adulto completa su propio ciclo, lo ideal es desarrollar una sabiduría y una filosofía trascendente de la vida. Erikson sostiene que hay que tratar de obtener la integridad sin caer en la desesperanza. Un sentimiento que puede surgir por varios motivos: las generaciones más jóvenes ya no necesitan a los adultos tardíos tanto como a los medios; el cuerpo del anciano empieza a fallar; las personas cercanas empiezan a morir y, por primera vez en el ciclo vital, se ve la muerte como un fin próximo y no como una posibilidad remota. 
Cuando surge la desesperanza, hay personas que empiezan a preocuparse por su pasado y por la manera en la que se desarrolló su vida. Tanto Don Pedro como la señora Bell sufren de esta debilidad y lloran en varios momentos del libro. Curiosamente, el momento de llanto más emblemático de Peter Pan es el desencadenante de la historia, cuando sus lágrimas por su sombra perdida despiertan a Wendy. Aquí, la señora Bell es una mezcla entre Wendy y Campanilla, las dos mujeres que amaron a Peter Pan y que, ahora, cuando éste ya parece estar cerca del final, le siguen amando. Esta crisis de senectud es porque, según su autora:

Don Pedro sabe que los niños se olvidarán de él y de sus días en su casa y llegará un momento en que la sombra lo cubra todo. La única esperanza es no olvidar. Si se hace esto, volverá a hacerse la luz. Y esto sólo se puede hacer desde la imaginación (Orozco, 2010).

\section{Conclusiones}

Decía James Kincaid que el niño es "aquello que no somos pero que casi somos. Aquello que anhelamos con tanta fuerza que casi nos ofende; aquello que nos parece ver en el espejo y que casi queremos poseer pero tememos hacerlo" (Kincaid, 1992: 1992). Al escribir como adulto sobre un niño eterno entramos en la que, según Nikolajeva, supone la mayor contradicción de la literatura infantil. Para ella, aunque todo escritor adulto, efectivamente, haya sido niño (y adolescente), existen unas diferencias tan profundas en experiencia vital y lingüística que siempre se va a proyectar una discrepancia o dualidad entre narrador y personaje (Nikolajeva: 2001).

Peter Pan, elaborado sobre una hipótesis de paradoja -un niño que nunca crece- recorre una trayectoria de doble, digna de los personajes más recordados de la literatura universal. Es un niño eterno, pero también es un niño inexistente (en Barrie, Loisel, Brom, Schumacher); es un ser de fantasía (en Disney, Loisel, Hogan, Fox) o parte de la realidad (en Spielberg, Kruesi, Orozco); un héroe romántico (en Hogan, Barry y Pearson) o un villano (en McCaughrean y Max); asesino (en Brom y Dietz) y en todas sus recreaciones, víctima de su propia dualidad.

La única verdad que importa en el país de Nunca Jamás es que uno es quien finge ser. De este modo, lo que viene a decir Peter Pan es que aunque no exista una eucatastrophe-o buena calamidad ${ }^{8}$ - al final de su historia, siempre se puede fingir que se ha obtenido el alivio. Un mensaje ciertamente contradictorio para un personaje que a pesar de no crecer nunca, sí nos enseña a aceptar que hay que hacerlo.

\footnotetext{
8 Decía Tolkien que todo final de cuento de hadas, por bondadosos o tremendos que fueran sus acontecimientos, debía provocar un corte de respiración, una efervescencia de corazón que prácticamente llevara a las lágrimas. Si la resolución era una buena calamidad que además de emocionarnos nos hacía sonreír, la llamaba eucatastrophe; si, sin embargo, se trataba de algo penoso o frustrante, recibía el nombre de dycatastrophe. (Tolkien, 2001: 68-69)
} 
Como ya preveía G. K. Chesterton poco después de que apareciera en escena (Chesterton, 1911), Peter Pan ha colmado las esperanzas de muchos. Niños, adultos, personajes ficticios se siguen asomando a la ventana esperando a Peter Pan. A los que ya están inventados, y a los que inventarán; porque dentro de su existencia, las crisis de su ciclo vital se pueden repetir una y otra vez. Eternamente.

De hecho, un artículo de marzo de 2011 anunciaba al menos cinco proyectos protagonizados por el personaje que abordarían nuevas crisis vitales: entre ellos, un romance a lo Crepúsculo"; un thriller con un psicópata llamado Pan y un policía apodado Garfio; y un drama que destaca la rivalidad entre los hermanos Peter Pan y James Garfio (Kit, 2011).

Al Peter Pan de Barrie -y a algunos de los derivados- se les privaba de la felicidad de la vida real que sólo podían contemplar a través de una ventana:

"Había vivido una infinidad de maravillas que ningún otro niño conocerá jamás; pero estaba viendo por la ventana la única alegría que le estará vedada para siempre". (Barrie, 2009: 255)

Otros autores sí que le concedieron crecer, ser feliz en alguna ocasión, sufrir, amar, divertirse; errar, de nuevo, en la segunda oportunidad. El personaje, en todas sus vidas, parece debatirse entre el grito ensordecedor de "¡Yo creo en las hadas! ¡Yo creo, sí creo!" y la reflexión shakesperiana de que "iLa culpa, querido Bruto, no es de nuestras estrellas, sino de nosotros mismos, que consentimos en ser inferiores!"

Peter Pan, como niño eterno, aboga tanto por las hadas de la fantasía como por el escepticismo de la realidad, con lo que se le recreará, sin cesar, mientras se sigan inventando historias. Al fin y al cabo, estar en crisis permanente es el único requisito imprescindible para existir.

\footnotetext{
${ }^{9}$ Saga literaria de la norteamericana Stephenie Meyer y adaptada al cine con gran éxito entre el público adolescente.
} 


\section{BIBLIOGRAFÍA}

BARRIE, J. M. (1902): The Little White Bird, London: Hodder and Stoughton.

- (1904): Peter Pan or The Boy Who Wouldn't Grow Up. In Barrie, J. M. (1995). Peter Pan and Other Plays. Oxford: Oxford University Press.

- (1906): Peter Pan in Kensington Gardens. In Barrie, J. M. (1999). Peter Pan in Kensington Gardens. Peter and Wendy. Oxford: Oxford University Press.

- (1911): Peter and Wendy. In Barrie, J. M. (1999). Peter Pan in Kensington Gardens. Peter and Wendy. Oxford: Oxford University Press.

- (2009): Peter Pan. La Obra Completa. Madrid: Neverland.

BARRY, Dave; PEARSON, Ridley (2007): Peter y los cazadores de estrellas (traducción de Ana y Raquel Herrera). Madrid: Roca Editorial de Libros.

- (2009): Peter Pan y los ladrones de sombras (traducción de Raquel Herrera). Madrid: Roca Editorial de Libros.

- (2007): Peter and the Secret of Rundoon. New York: Hyperion Books.

- (2009): Peter and the Sword of Mercy. New York: Hyperion Books.

BAXTER, John (1996): Steven Spielberg: The Unauthorized Biography. London: Harper Collins.

BIRKIN, Andrew (1979): J. M. Barrie 107 The Lost Boys: The Love Story that Gave Birth to Peter Pan. New York: Clarkson N. Potter.

BROM (2009): The Child Thief. New York: Harper Collins.

CHESTERTON, G.K. (1911/1989): "Peter Pan as a Novel." The Nation (18 Noviembre 1911) en SENICK, Gerard J. (ed.), Children's Literature Review (1989) Vol. 16., Detroit: Gale Research.

CIOCIA, S. (2007): "The boy who must not grow up: Geraldine McCaughrean's Twenty-first Century Peter Pan". New Review of Children's Literature and Librarianship, Vol. 13, No. 1.

ERIKSON, Erik (1974): Identidad, juventud y crisis. Buenos Aires: Paidós.

DIETZ, Damion (2010): "Entrevista personal de la autora con Damion Dietz", Nueva York: 1 de mayo, 2010.

FOX, Laurie (2004): The Lost Girls. New York: Simon \& Schuster.

HART, James V. (1990): Hook. The Return of the Captain [en línea]. En: 〈http://www.awesomefilm.com/script/hook1.pdf〉[Consulta: 9 de enero 2009]

HERREROS DE TEJADA, Silvia (2009): Todos crecen menos Peter. La creación del mito de Peter Pan por parte de J. M. Barrie. Madrid: Lengua de Trapo. 
JACK, R. D. S. (1991): The Road to the Never Land. A Reassessment of J. M. Barrie's Dramatic Art, Aberdeen: University Press.

- (2010) Myths and the Mythmaker. A Literary Account of J. M. Barrie's Formative Years. Amsterdam/ New York: Editions Rodopi.

KIDD, Kenneth (1996): "Men Who Run With Wolves and the Women Who Love Them: Child Study and Compulsory Heterosexuality in Feral Child Films", en The Lion and the Unicorn, Vol. 20, Issue 1.

KILEY, Dan (1984): The Peter Pan Syndrome: Men Who Have Never Grown Up. New York: Avon.

KINCAID, James (1992): Child-loving: The Erotic Child and Victorian Culture. New York: Routledge.

KIT, Borys (2011): "Why Peter Pan Projects are Infiltrating Hollywood" [en línea] 〈http://www.hollywoodreporter.com/heat-vision/why-peter-pan-projects-are-16895»

[Consulta: 2 de febrero 2012]

KRUESI, Mary Alice (1999): Second Star to the Right. New York: Avon Books.

LOISEL, Régis (2004): Peter Pan, Opikanoba, Tempestad, Manos Rojas, Garfio, Destinos. Barcelona: Ediciones Glénat.

MALTIN, Leonard (1995): The Disney Films. New York: Hyperion, 1995.

MAX (1991): Peter Pank. Barcelona: Max \& Ediciones La Cúpula.

MCCAUGHREAN, G. (2006): Peter Pan de rojo escarlata. Madrid: Alfaguara.

MCKEE, R. (2005): El guión. Barcelona: Alba Editorial.

NIKOLAJEVA, Maria (2001): "The changing aesthetics of character in children's fiction", en Style Journal, Vol. 35, Issue 3.

OROZCO AMORÓS, Paloma (2005): La sombra de Peter Pan. Madrid: San Pablo.

- (2010) "Entrevista personal con la autora". Email: 6 de mayo, 2010.

SHAKESPEARE, William (2001). Julio César. Madrid: Espasa-Calpe.

SHEEHAN, H. (2001): "Trust the Teller. Henry Sheehan talks with James V. Hart about Dracula", en VINCENDEAU, Ginette (ed.), Film, Literature, Heritage. A Sight and Sound reader. London: British Film Institute.

TOLKIEN, J. R. R. (2001): Tree and Leaf. London: Harper Collins. 
TROUSSON, Raymond (1965): Un problème de Littérature Comparée: les études de thèmes, París: Lettres Modernes.

WREN, Celia (2003): "Fear of Flying: The Perennial Peter Pan is Buoyant Children's Fare, Right? Think Again." American Theatre, Vol. 20, n² 2.

\section{FILMOGRAFÍA}

BUDD, Robin y COOK, Donovan (dirs.). (2002): Regreso a Nunca Jamás (Return to Neverland). Estados Unidos: Walt Disney Pictures.

DISNEY, Walt (2005): Por qué hice Peter Pan (Why I did Peter Pan). En GERONIMI et al. Peter Pan. [Edición especial platino]. Estados Unidos: Walt Disney Pictures.

GERONIMI, Clyde, LUSKE, Hamilton y JACKSON, Wilfred (dirs.) (1953): Peter Pan. Estados Unidos: Walt Disney Pictures.

HOGAN, P.J. (dir.) (2003): Peter Pan. Estados Unidos: Columbia.

SCHUMACHER, Joel (dir.) (1987): The Lost Boys (Jóvenes ocultos). Estados Unidos: Miramax.

SPIELBERG, Steven (dir.) (1991): Hook. Estados Unidos: Amblin Entertainment / TriStar Pictures. Aronofsky, 2010). 